\title{
Helping Students Write it Right: Instilling Good Report Writing Habits in a Linear Circuit Lab Course
}

\section{Dr. Eva Cosoroaba, University of Vermont}

Eva Cosoroaba is a lecturer in the Electrical and Biomedical Engineering Department at the University of Vermont. She received her PhD form the University of Texas at Dallas in December of 2017. Cosoroaba was a research assistant in the Renewable Energy and Vehicular Technology (REVT) Laboratory and a teaching assistant at UT Dallas. Her expertise lies in electric machines and design, multiphysics simulations, and magnetohydrodynamics and its possible use for emission free power generation. Dr Cosoroaba's current research interest is engineering education with focus on mastery learning, the effect of social networks in the classroom on student learning and efficient implementation of active learning. 


\section{Helping Students Write it Right:}

\section{Instilling Good Report Writing Habits in a Linear Circuit Lab Course}

\section{Introduction}

Writing is often not on the top of student's priority list when it comes to their laboratory experience. This is reflected in the quality of the lab reports they submit. While grading and providing feedback to students on these reports, the instructor often gets slowed down and disconcerted by a lack of consideration for formatting, a convention crucial to effective written communication. This can manifest in results without context and data figures with no legends (rendering both meaningless) or lack of section subtitles or paragraph structure. Another often seen symptom is a result comparisons comprised of placing two figures or two numbers next to each other with no quantification or written summary of differences. The instructor is left to wonder if these manifestations are symptoms of carelessness, of fundamental misconceptions related to the course content, or worse, a lack of critical thinking.

In order to increase the quality of written lab reports, the sophomore level "Linear Circuits Analysis Laboratory I" (EE 081) course adopted a version of "Specifications Grading", as outlined in Linda Nelson's book of the same title [1], in Fall 2018. Though the main goal of this teaching and grading intervention was to raise the quality of student writing, it was anticipated that this type of grading would bring secondary benefits. These include instilling good writing habits in general for follow up lab courses as well as provide more transparency and consistency in grading. The principles of specifications grading are detailed in Section 2 of this paper alongside the adaptations made for this introductory electrical engineering lab course. The results of the intervention are laid out in Section 3, from both a student and instructor perspective. Section 4 includes changes in the grading method adopted in future offerings of the course, followed by general conclusions in Section 5.

\section{Applied Specifications Grading}

Specifications grading, also called "specs grading", is a grading system that focuses on mastery in learning [1]. This means that less weight is placed on the students' ability to prove their competency at a single, specified moment in time. Instead, mastery of this competency is built by completing assignments that repeatedly practice the same skills. Clear feedback and concrete suggestions for improvement are at the core of this method [2].

Another feature of specs grading is that it relies on "backward course design" [1], [3], in which the desired learning outcomes are set first, followed by what is considered an adequate proof of learning and lastly, course content and activities are designed to teach students [4]. This results in higher assessment rigor, as students will not be able to pass a course without mastering essential learning outcomes [5], but also transparency [6], as students are provided clear guidelines and expectations. 
The principles of specs grading were applied to the lab course as follows. The course grading was divided into three components, each assessing two specific learning outcomes of the course. Components 1 and 2 were a practical, hands-on midterm and final exam respectively, in which students demonstrated Learning Outcome 1: "Build and analyze circuits on breadboards in a lab setting (using a DMM, voltage source, oscilloscope)" and 2: "Simulate circuits using PSpice to find specific circuit parameters". Component 3 consisted in the lab reports which practiced and tested Learning Outcome 3: "Compare experimental and theoretic (analytic and numerical) results and demonstrate the reason behind divergence in results" and 4: "Write clear lab reports, present data in an orderly way and describe lab procedures." The final grade was computed as the average of the three.

Students were provided a list of clear specifications ("specs") for each assignment, which doubled as a rubric, at the beginning of the semester as part of the Syllabus. Table 1 shows the specs of the practical midterm and final exam. Students practiced the skills tested for every week during the lab. Additionally, dedicated lab sessions were set aside to conduct mock practical midterm and final exams. As can be seen, the assignment is fully geared towards testing for Learning Outcomes 1 and 2. This simplified assessment, reduced subjectivity in grading as well as helped students know how to prepare for the practical tests and what is expected of them.

TABLE 1 - GRADING SPECS FOR GRADE COMPONENTS 1 AND 2

\begin{tabular}{|c|c|}
\hline Passed Hurdle & Letter Grade Components 1 and 2 \\
\hline $\begin{array}{l}\text { Arrived at correct measurement } \underline{\text { AND }} \\
\text { simulation result AND analytic result }\end{array}$ & $\mathrm{A}+$ \\
\hline $\begin{array}{c}\text { Arrived at correct measurement AND } \\
\text { simulation result }\end{array}$ & A \\
\hline $\begin{array}{c}\text { Arrived at correct measurement } \underline{\mathrm{OR}} \\
\text { simulation result }\end{array}$ & B \\
\hline $\begin{array}{l}\text { Build circuit } \frac{\text { AND }}{\text { diagram correctly }} \\
\text { diagrion wiring }\end{array}$ & $\mathrm{C}$ \\
\hline $\begin{array}{l}\text { Build circuit } \underline{\mathrm{OR}} \text { simulation wiring } \\
\text { diagram correctly }\end{array}$ & $\mathrm{D}$ \\
\hline Nothing correct & $\mathrm{F}$ \\
\hline
\end{tabular}

In the case of the lab reports, assignments were graded Satisfactory Quality (SQ) or Not Satisfactory Quality (NSQ) with one missed spec resulting in a NSQ report. At the end of the semester, the number of SQ reports determined students' grade on the report component of the lab, according to Table 2. The detailed list of specs is included in Appendix A, as provided to the students at the beginning of the semester. Each report was graded against the list of forty specs. There are three categories of specs: administrative, formatting and content related specs. The administrative specs include lab attendance and timely submission of work. Formatting specs detail the requirements for the cover page of the report, captioning of figures and tables, numbering of equations and use of units. This section also specifies that any figures, tables or equations in the report must be mentioned or referenced to in the report text. This assures that students explicitly provide context for these supporting materials. Lastly, the content related specs outline the requirements for each section of the report. Here it is made explicitly clear that comparisons 
between results must be described in words in addition to data tables or figures, to counteract some of the symptoms of inadequate writing mentioned in the introduction.

TABLE 2 - GENERAL GRADING SPECS FOR GRADE COMPONENT 3 (9 TOTAL REPORTS)

\begin{tabular}{|c|c|}
\hline Number of SQ - Reports & Component 3 Letter Grade \\
\hline 9 & $\mathrm{~A}+$ \\
\hline 8 & $\mathrm{~A}$ \\
\hline 6 & $\mathrm{~B}$ \\
\hline 4 & $\mathrm{C}$ \\
\hline 2 & $\mathrm{D}$ \\
\hline 1 or less & $\mathrm{F}$ \\
\hline
\end{tabular}

To encourage mastery, students were allowed to submit revisions of reports using a token system. Students started the semester with two tokens, called "resistors", but had the opportunity to earn more throughout the semester by completing reflective journal entries after each lab. See Appendix $\mathrm{B}$ for the instructions given to students regarding this extra credit work. The journal questions were a metacognitive exercise, to help students reflect on their lab experience and improve it over time. The tokens themselves could be used in two ways: either to resubmit an NSQ report or to preemptively extend the original submission deadline of the report. See Appendix $\mathrm{C}$ for the Syllabus section regarding tokens.

\section{Student Reception and Instructor Observations}

At the end of the semester, students filled out a voluntary, anonymous survey in which 23 of 31 students participated. Students surveyed largely acknowledged that specifications grading pushed them to be more attentive to requirements and that it raised the quality of their work. However, they also reported drawbacks.

To the open-ended question "What did you like or not like about specifications grading? Please explain with specifics." 9 students reported only positives, 10 had mixed feedback and 4 students reported only negative aspects of this grading paradigm. Amongst the benefits, students generally appreciated the overall consistency and clarity in expectations, the report rubric and the syllabus (14 students) and the opportunity to resubmit and improve their work (4 students): "I liked the specification grading because I knew exactly what to write for every lab report. Also, when I got NSQ's for small mistakes I was less likely to forget the next time so it helped me not have to resubmit labs in the future."

On the other spectrum, students perceived the system to be initially difficult to understand and/or harsh (8 students): "A grading scale based on either pass or fail was very extreme at first. The concept behind the system is understandable, but failing an entire lab report due to a missing figure title is a stretch". Some noted that due to specs and resubmissions more work and, specifically more accurate work was required of them (3 students): "The only downside was that it was a little bit annoying that you had to make everything absolutely correct." 
To the question, "What did specs grading help you do in this course?" students cited consistency in report quality and better writing habits (16 students): "The specifications grading system kept me from giving up on certain aspects of writing the lab reports, because I would have probably just settled for a $90 \%$..."

Lastly, to the prompt: "Now that you have experienced specifications grading, would you like to see other classes and/or instructors use it?" 22 students would like to see specs implemented in other courses: "If the system is used in a similar manner I wouldn't mind seeing it in other classes. Being able to understand your mistakes, correct them, and resubmit without a penalty is a great opportunity." Six of them specified that they could see it used in lab classes but not lecture style courses: "I think specifications grading works for a lab, but I don't know that it would be reasonable for other classes. Partial credit on things really saves students from failing classes and also sometimes you can know all of the theory and concepts and that's seen in your work, but you just make a few mistakes. Having it marked as wrong even if you're mostly right would be too stressful and not accurate to what's important. For example, if I do a math problem and I do everything right and then on the last line of math I make a small mistake, the answer I get will be wrong, but I showed that I knew how to do the problem I just made a small error because I'm human and people mess up. Specification grading can work for a lab though."

From an instructor perspective, using specifications grading has had the hoped effects. It improved report quality as compared to previous years. The work was more structured and students were overall less likely to submit incomplete work and showed more care for the details of typical writing conventions and mechanics such as section headings and figure and table captions. To quantify this observation, the specs graded EE 081 reports (first submission only) of the students in this study were compared to reports from the previous student generation. Unfortunately, the instructor only had access to the EE 082 course materials (second course in the circuit laboratory sequence) which includes students who have more experience in report writing then the EE 081 cohort. Nonetheless, when assessing reports on whether or not students included table and figure captions (one of the specs criteria), student maturity and practice of report writing did not seem to have been a factor. This is illustrated in Fig. 1. Furthermore, it was found that there are sizable differences between reports at the beginning and at the end of the semester. For the EE 082 cohort, where figure and table capturing was not an explicit grading factor and only loosely enforced, the number of students that made an effort in this area dropped over the semester. On the other hand, the EE 081 cohort, where specs grading was used, at the end of the semester almost all students made sure to adhere to the figure and table capturing criteria in their first submission attempt. 


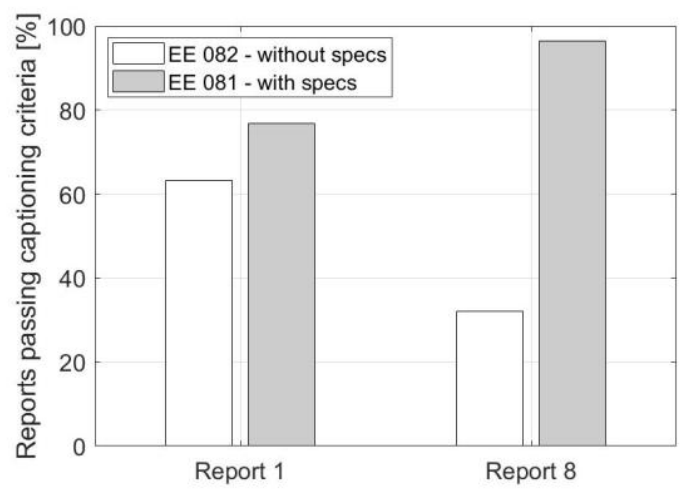

FIGURE 1 - QUANTITATIVE COMPARISON OF REPORTS WITH AND WITHOUT SPECS

Other benefits seen by the instructor were grading consistency and transparency due to the detailed and explicit rubric. Lastly, due to the backward course design approach, the Learning Objectives were the center of assessment, allowing the instructor to be confident that the students mastered the outcomes at the end of the semester. As a downside from the instructor's perspective, the token system can be cumbersome to keep track of. The system that worked in the Fall 2018 offering of EE 081 was that the instructor, who read and replied to the extra credit journal entries, added tokens to the students stash (a column in the online grade center) whenever they earned a new token. The teaching assistant removed tokens whenever the students requested to use them, as well as took care of all report grading. Without a trusted, well-organized and consistent teaching assistant who understands the educational value of this grading system with whom communication is open and honest, this system will become difficult.

\section{Implementation Changes in Future Course Offerings}

Even though specs grading was positively received and succeeded in achieving the hoped outcome, some students (three) raised the issue of perceived performance pressure and workload due to revisions: "The pressure to get the lab reports right on the first try was pretty intense. Especially if you made one mistake, you'd still get the entire lab wrong and then you'd have to re-do it. Redoing it was never very challenging, but it still added extra pressure during the week while you're trying to do the next lab report." This, as well as the instructor observations, prompted some changes to the Fall 2018 specs grading method for the Fall 2019 offering.

Firstly, it was recognized that it does not require nine perfect lab reports for a student to demonstrate that they have mastered the mechanics of lab report writing. In response to this, the number of reports that need to meet all specs/criteria was reduced. This reduction allowed the elimination of the token and revision system, without sacrificing the mastery learning aspect, as students receive feedback without penalization and can learn from the feedback for future report submissions.

Secondly, the purpose of report writing was reassessed and changes were made accordingly. The purpose of lab reports is partly to provide students a space to think critically about their results and grapple with discrepancies between theory and practice as well as assure that students spend time 
with the course content outside the classroom. Partly the role of reports is to get students accustomed to work place practices of sharing experimental results and information with colleagues. Typically, each company will have their own preferred template and students will have to be prepared to work with a variety of reporting methods. Due to this new view on the role of lab reports, students are tasked to complete two different types of reports: comprehensive reports (CR) in the style of the 2018 offering using the same forty specs rubric and quick reports (QR) with their own specs rubric. Quick reports are in a power point format, improving student's ability to summarize concepts and focus on providing only essential information. Table 3 summarizes the new report grade component requirements.

TABLE 3 - REVISED REPORT COMPONENT GRADE REQUIREMENTS (9 TOTAL REPORTS)

\begin{tabular}{|c|c|c|c|}
\hline Letter Grade & Total Reports Submitted & CRs that meet all criteria & QRs that meet all criteria \\
\hline A & 9 & 2 & 4 \\
\hline B & 9 & 1 & 3 \\
\hline C & 8 & 0 & 2 \\
\hline D & 7 & 0 & 1 \\
\hline F & Less than 7 & 0 & 0 \\
\hline
\end{tabular}

\section{Conclusions}

Overall, specs grading did notably improve students report quality from both the instructor and student perspective in the Fall 2018 offering of "Linear Circuits Analysis Laboratory I" (EE 081). It is therefore worthwhile to assess the use of this method in other courses as well. However, some of the improvements seen were not necessarily due to the complete overhaul of the course to specs grading but to certain aspects of the specs grading paradigm. Specifically grading transparency through very detailed rubrics seemed to have had a significant impact on student's satisfaction with the course experience. This is encouraging, as it means that course improvements can be made incrementally while still securing some of the benefits of specs grading, without fully shifting to a pass-fail grading system.

\section{References}

[1] - L. B. Nilson, Specifications Grading: Restoring Rigor, Motivating Students, and Saving Faculty Time, Sterling, VA: Stylus Publishing, 2015.

[2] - T. R. Guskey, and L. A. Jung, "Response-to-intervention and mastery learning: tracing roots and seeking common ground," The Clearing House, vol. 84, no. 6, pp. 249-255, 2011

[3] - M. W. Bonner, "Grading rigor in counselor education: a specifications grading framework," Educational Research Quarterly, vol. 39, no. 4, pp 21-42, 2016

[4] - G. G. Shaker, and S. K. Nathan, "Teaching about celebrity and philanthropy: a case study of backward course design," The Journal of Nonprofit Education and Leadership, vol. 8, nr. 4, pp 403-421, 2018

[5] - J. Ring, "Specifications Grading in the Flipped Organic Classroom," Journal of Chemical Education, vol. 94, no. 12, pp 2005-2006, 2017

[6] - L. Pope, H. B. Parker, and S. Ultsch, “Assessment of specifications grading in an undergraduate dietetics course," Journal of Nutrition Education and Behavior, available online August 2019 
Appendix A: Lab Report Specs - EE 081, Fall 2018

\begin{tabular}{|c|c|c|}
\hline Spec Category & Pass & Fail \\
\hline $\begin{array}{l}\text { Lab attendance (checked by } \\
\text { TA at time of Lab) }\end{array}$ & Preset & Absent \\
\hline Report Submission & $\checkmark \quad$ before or on time & \multirow{12}{*}{ 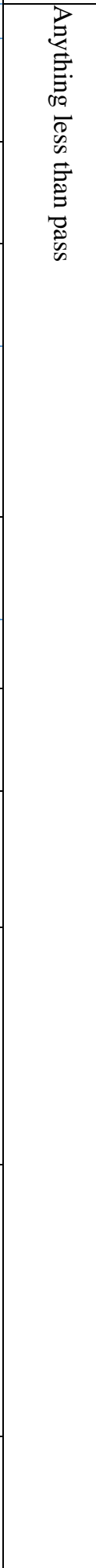 } \\
\hline Report Structure & $\begin{array}{l}\checkmark \text { Contains all } 6 \text { sections ("Introduction", "Analytic Modeling } \\
\text { Results", "Numerical Modeling Results", "Experimental } \\
\text { Results", "Data Comparison", "Conclusions") }\end{array}$ & \\
\hline Title & $\begin{array}{ll}\checkmark & \text { lab name (from lab manual) } \\
\checkmark & \text { lab number } \\
\checkmark & \text { date of experiment }\end{array}$ & \\
\hline Team Member & $\begin{array}{ll}\checkmark & \text { all names } \\
\checkmark & \text { role in parenthesis (circuit checker or builder) } \\
\checkmark & \text { report author name underlined }\end{array}$ & \\
\hline All Figures and Tables & $\begin{array}{ll}\checkmark & \text { clearly readable } \\
\checkmark & \text { show units } \\
\checkmark & \text { captions numbered in order (figures and tables separately) } \\
\checkmark & \text { a brief description caption above table or underneath figure } \\
\checkmark & \text { mentioned/pointed to in the text body }\end{array}$ & \\
\hline All Equations & $\begin{array}{ll} & \text { numbered } \\
\checkmark & \text { final numerical values have units } \\
\checkmark & \text { mentioned/pointed to in the text body }\end{array}$ & \\
\hline "Introduction" Content & $\begin{array}{ll}\checkmark & \text { brief introduction to the theory needed to understand the lab } \\
\checkmark & \text { description of the goal of the lab and report }\end{array}$ & \\
\hline $\begin{array}{l}\text { "Analytic Modeling Results" } \\
\text { Content }\end{array}$ & $\begin{array}{ll}\checkmark & \text { picture of the circuit schematic (example uses Fritzing) } \\
\checkmark & \text { circuit component values and source values given in words } \\
\checkmark & \text { calculations with result(s) }\end{array}$ & \\
\hline $\begin{array}{l}\text { "Numerical Modeling } \\
\text { Results" Content }\end{array}$ & $\begin{array}{ll}\checkmark & \text { picture of the simulation wiring diagram (from PSpice) } \\
\checkmark & \text { circuit component values and source values in words } \\
\checkmark & \text { simulation conditions in words } \\
\checkmark & \text { figure or table of result(s) or mentioned in text }\end{array}$ & \\
\hline $\begin{array}{l}\text { "Experimental Results" } \\
\text { Content }\end{array}$ & $\begin{array}{ll}\checkmark & \text { picture of experimental setup } \\
\checkmark & \text { circuit component values and source values in words } \\
\checkmark & \text { error equation } \\
\checkmark & \text { table containing theoretical component values, measured } \\
& \text { component values and errors between the two } \\
\checkmark & \text { description of measurement method(s) in words } \\
\checkmark & \text { figure or table of result(s) or result(s) mentioned in text }\end{array}$ & \\
\hline "Data Comparison" Content & $\begin{array}{ll}\checkmark & \text { table summarizing all relevant results for all } 3 \text { methods } \\
& \text { (analytic, numeric and experimental) } \\
\checkmark & \text { identification of differences and similarities between all } \\
\text { method results in words } \\
\checkmark & \text { IF DIFFERNECES: values for error in relevant results in } \\
& \text { words or table } \\
\checkmark & \text { IF ERROR >5\%: explanation of causes for differences } \\
\checkmark & \text { IF ERROR >5\%: prove explanation }\end{array}$ & \\
\hline "Conclusion" Content & $\begin{array}{ll} & \text { brief summary of report content } \\
\checkmark & \text { brief summary of data comparison result } \\
\checkmark & \text { IF ERROR >5\%: brief summary of causes for result } \\
& \text { differences }\end{array}$ & \\
\hline
\end{tabular}




\section{Appendix B: Lab Reflection Instructions - EE 081, Fall 2018}

"Submitting two meaningful and honest lab reflection earns you one resistor token.

Reflections are due EOD, the day of your lab. Example, if your lab is Thursday from 10am to 12:30pm your journal entry is due Thursday 11:59pm.

Copy and paste the three questions below into your journal post and answer them with minimum 2 , maximum 4 sentences each.

1) What went well during this lab and why?

2) What did not go well and why?

3) What will you do to have a better lab experience next time?"

\section{Appendix C: About the Token System from the Syllabus}

“Token System: Practice makes perfect, but until then, we have a token system of "resistors" to help you out in a pinch. Everyone starts with two (imaginary) resistors. To use a resistor, email the TA \& instructor (CC) and let your intentions known in advance. Tokens cannot be used retroactively. Resistors are tallied in the BB grade center.

Use a Resistor: 1) To buy a resubmission of an NSQ report. Note: each report be revised only once. E-mail regarding token use must be submitted by EOD (end-of-day, 11:59pm) the day following grade posting and revised reports are due three days after grades were posted, EOD.

Example: If report grades are posted Monday, e-mail is due Tuesday EOD and report revision Thursday EOD.

2) To get a 24-hour extension on the lab report submission deadline. Note: two resistors can be redeemed for a 48-hour extension. You will have to specify the number of resistors you plan to use via e-mail the day before the report is due, by EOD. You cannot extend the same deadline twice. Therefore carefully decide if you need 24 or more hours.

Example: If the report is due Tuesday, EOD, you have to notify if you would like a two day extension latest Monday EOD. If your tokens permit it, your report will now be due Thursday EOD and your resistor stash drops by 2 .

Earn a Resistor: by submitting two lab reflection journals (two reflections $=1$ resistor). These journal entries are confidential and only read by the instructor. Details on Blackboard.

Earn the Golden Resistor: at the end of the semester, the student(s) with the highest letter grade and highest number of resistors collected will be awarded with the OFFICIAL GOLDEN RESISTOR of EE 081 in recognition of their consistency in SQ work." 